УДК 621.395 .12

\title{
АВТОМАТИЧЕСКИЙ СИНХРОНИЗАТОР ЦИФРОВЫХ СИГНАЛОВ И ТЕЛЕКОММУНИКАЦИОННЫХ ПОТОКОВ
}

\author{
А. Б. КОХАНОВ \\ Одесский национальный политехнический университет, \\ Украина, Одесса, 65044, пр-т Шевченко 1
}

\begin{abstract}
Аннотация. В работе предложен принцип построения автоматического цифрового синхронизатора цифрового или битового потока данных от первичного эталонного генератора генераторного оборудования телекоммуникационной сети без передачи сигналов синхронизации от эталонного генератора сети. Этот принцип возможно использовать в оптических транспортных сетях OTN (optical transport network), кабельных каналах, а также в радиоканалах сетей 5G (10-100 Гбит/с). Автоматический цифровой синхронизатор позволяет принимать асинхронные сигналы в синхронном режиме (RS 232C, CAN), сохраняя синхронный режим работы компьютерной или телекоммуникационной сети с полным устранением вандера и значительным снижением джиттера.
\end{abstract}

Ключевые слова: частотная синхронизация; битовый поток; телекоммуникационная система; интерфейс; цифровой; качество; сеть синхронизации

Синхронизация является средством поддержания качественной работы цифрового оборудования в сетях связи, различных микропроцессорных интерфейсах, центрах обработки и хранения данных на одной скорости. К устройствам синхронизации всегда предъявляются повышенные требования с точки зрения стабильности работы для обеспечения синфазности принимаемого сигнала и сигнала синхронизации.

Синхронизация цифровых сетей в обобщенном виде является задачей синхронизации цифровых последовательностей, которые могут быть синхронизированы:

1) по длительности временного интервала $T$ (период повторения) или частоте $f=1 / T-$ частотная синхронизация;

2) по начальной фазе $\varphi$ синхронизируемого сигнала - фазовая синхронизация;
3) по времени прихода $t$ в устройство или систему сигнала (пакета) - временная синхронизация.

В современных телекоммуникационных системах (ТС) и локальных компьютерных сетях (ЛКС) используются все три вида вышеперечисленных типов синхронизации. Задача временной синхронизации носит глобальный характер и решается разными способами с помощью службы единого времени (UTC), навигационных систем GPS/ГЛОНАС и т.д. Фазовая синхронизация важна для конкретного устройства (компьютерный интерфейс, регенератор, мультиплексор и т.д.), и реализуется с помощью систем фазовой автоматической подстройки частоты (ФАПЧ), что также позволяет устранить джиттер [1-3].

Частотная синхронизация является самым проблемным видом синхронизации, т. к. актуальна для всех элементов ТС и ЛКС, и решается 


\section{БИБЛИОГРАФИЧЕСКИЙ СПИСОК}

1. Слепов, Н. “Синхронизация цифровых сетей. Методы, терминология, аппаратура,” Электроника: Наука, технология, бизнес, № 2, С. 24-29, 2002. URI: http://www.electronics.ru/journal/article/1312.

2. Сухман, С.М.; Бернов, А.Б.; Шевкопляс, В.Б. Синхронизаиия в телекоммуникаиионных системах. М.: Эко-Трендз, 2003, 272 с. ISBN 5-88405-046-1. URI: https://www.rfbr.ru/rffi/ru/books/o 36724.

3. Avivi, Rotem; Kerner, Michael; Shumaker, Evgeny; Puma, Giuseppe Li; Sela, Tami; Sofer, Lidor; Horovitz, Gil. "Adaptive spur cancellation technique in 
all-digital phase-locked loops," IEEE Trans. Circuits Systems II: Express Briefs, Vol. 64, No. 11, p. 1292-1296, 2017. DOI: $10.1109 /$ TCSII.2017.2650782.

4. Иванов, В.И.; Гордиенко, В.Н.; Попов, Г.Н.; и др. Цифровые и аналоговые системы передачи: Учебник для вузов. Под ред. В.Н. Иванова. 2-е изд. М.: Горячая линия-Телеком, 2003. 232 с. ISBN 5-93517-116-3.

5. ITU-T Recommendation G.822. Controlled Slip Rate Objectives on an International Digital Connection (Extract from the Blue Book).

6. Гордиенко, В.Н.; Крухмалев, В.В.; Моченов, А.Д.; Шарафутдинов, Р.М. Оптические телекоммуникационные системы. Учебник для вузов. Под ред.
В.Н.Гордиенко. М.: Горячая линия-Телеком, 2011. 368 c. ISBN 978-5-9912-0146-9.

7. Коханов, А.Б. “Технология синхронного детектирования сигналов,” Известия вузов. Радиоэлектроника, Т. 50, № 11, С. 14-25, 2007. URI: http://radio. kpi.ua/article/view/S0021347007110027.

8. Патент Украины № 11902 от 10.12.2019. Опубл. Бюл. Изобр., № 7, “Промислова власність”.

9. “О технологии 5G," Huawei web-site. URI: https://www.huawei.com/minisite/russia/5g/about.html.

10. "5G technology vision," 2015. URI: https:// telecom-knowledge.blogspot.com/2015/12/5g-technolog y-vision.html. 